\title{
Antioxidant and Tyrosinase Inhibiting Activities of Ethylacetate, Methanolic and Aqueous Extracts of Basella alba Leaves
}

\section{Arokoyo DS ${ }^{*}$, Oyeyipo IP², Du Plessis SS${ }^{2}$, Popoola $\mathrm{OK}^{3}$ and Aboua $Y^{1}$}

${ }^{1}$ Department of Biomedical Sciences, Cape Peninsula University of Technology, South Africa

2Division of Medical Physiology, Stellenbosch University, South Africa

${ }^{3}$ Department of Chemistry, Ekiti State University, Nigeria

\section{Research Article \\ Volume 4 Issue 4}

Received Date: August 13, 2019

Published Date: October 14, 2019

DOI: $10.23880 /$ act- 16000166

${ }^{*}$ Corresponding author: Dennis S Arokoyo, Department of Biomedical Sciences, Faculty of Health and Wellness Sciences, Cape Peninsula University of Technology, Bellville, Cape Town, South Africa, Tel: +27742831856; E-mail: dennisarokoyo@yahoo.com

\section{Abstract}

Basella alba is a leafy green plant commonly cultivated and consumed as vegetable in many Asian and tropical African communities. The plant has been scientifically proven to possess a number of beneficial effects including antioxidant effect. This study was aimed at investigating comparatively, the flavonoids content, the antioxidant and antityrosinase activities of ethylacetate, methanol and aqueous extract of Basella alba leaves and establish a possible relationship among these parameters. Two flavonoids, namely flavanol and flavonol were quantitatively measured in the extracts and antioxidant capacities assessed using TEAC, ORAC and FRAP assays. The result showed that ethylacetate extract contains much higher concentrations of flavanol and flavonol when compared to both methanol and aqueous extracts which contain negligible amounts of the two flavonoids. Values of antioxidant capacities were as follows; Aqueous (TEAC = $439.90 \pm 0.07 \mu \mathrm{mol} \mathrm{TE} / \mathrm{g}$, ORAC $=1384.40 \pm 90.65 \mu \mathrm{mol}$ TE$/ \mathrm{g}$, FRAP $=48.17 \pm 0.00 \mu \mathrm{mol} \mathrm{AAE} / \mathrm{g})$, ethylacetate (TEAC $=$ $61.30 \pm 0.07 \mu \mathrm{mol} \mathrm{TE} / \mathrm{g}$, ORAC $=483.09 \pm 35.00 \mu \mathrm{mol}$ TE$/ \mathrm{g}, \mathrm{FRAP}=117.99 \pm 0.01 \mu \mathrm{mol} \mathrm{AAE} / \mathrm{g})$ and methanol $(\mathrm{TEAC}=$ $44.20 \pm 0.03 \mu \mathrm{mol} \mathrm{TE} / \mathrm{g}, \mathrm{ORAC}=1286.25 \pm 9.00 \mu \mathrm{mol} \mathrm{TE} / \mathrm{g}, \mathrm{FRAP}=46.64 \pm 0.00 \mu \mathrm{mol} \mathrm{AAE} / \mathrm{g})$. All three extracts had inhibitory activity against tyrosinase at effective concentrations of $193.58 \pm 0.02,203.33 \pm 0.02$ and $222.83 \pm 0.03 \mu \mathrm{g} / \mathrm{mL}$ for aqueous, methanol and ethylacetate extracts respectively. It was concluded from the results that the aqueous extract of Basella alba leaves produced the best antioxidant and antityrosinase activities and the two actions may be directly related. 
Abbreviations: ATP: Adenosine Triphosphate; ROS: Reactive Oxidative Species; SOD: Superoxide Dismutase; GPx: Glutathione Peroxidase; CX: Cardiac Xenobiotics

\section{Introduction}

Basella alba (Family: Basellaceae) is a climbing perennial herb with deep-green, heart-shaped leaves and bears fleshy dark bluish fruits [1]. It is commonly cultivated and consumed as vegetable in many Asian and tropical African communities. Basella alba have being used traditionally for its diverse health benefits and have been scientifically proven to possess anti-inflammatory, analgesic, antioxidant, antifungal, anticancer, androgenic and red cell membrane-stabilizing properties among others [2-4]. Of particular importance to this study is the possibility of a correlation between the antioxidant property of the plant and its reported use in skin care by Bangledeshians for the prevention of freckles. This presumption is based on the background knowledge that oxidative stress can contribute significantly to skin aging by stimulating the activities of skin-damaging enzymes like tyrosinase [5].

Tyrosinase (Polyphenol oxidase) is a coppercontaining endogenous enzyme which plays a role in the initial steps in melanin biosynthesis that result in the conversion of L-tyrosine to dopaquinone via consecutive hydroxylation and oxidation reactions [6,7]. The enzyme is widely distributed in microorganisms, animals and plants. Due to inhibition of enzymatic oxidation, antityrosinase agents have become increasingly significant in cosmetics, medicine as well as in the agricultural sector for the prevention of hyperpigmentation and elongation of the life span of perishable agricultural products [8-11]. Kojic acid, arbutin and hydroquinones are substances with proven tyrosinase inhibiting activities, but their use in humans have been limited due to the deleterious effects on mammalian cells [6]. This necessitated the investigation of many natural substances with antityrosinase activities including Basella alba, most of which are medicinal plants with high composition of phenolic compounds like flavonoids [5]. Flavonoids are said to be the most abundant phenolic compounds present in all parts of most plants and are capable of exerting potent antioxidant activities in biological systems both in vivo and in vitro [12]. Over 6000 biologically active flavonoids have been identified and of these, flavonols appears to be the most important especially in offering protection against oxidative stress and ultraviolet radiation [13].

The antioxidant activity of plant extracts can be assessed using a wide range of biochemical assays which in essence measures the quantity and potency of antioxidant phytochemicals in the extracted material. A large number of these methods of assessment including trolox equivalent antioxidant capacity (TEAC) and ferric reducing antioxidant power (FRAP) are based on colorimetric reactions [14]. The TEAC method assesses the ability of compounds to scavenge ABTS $\left(2,2^{\prime}\right.$-azinobis(3-ethylbenzothiazoline)-6-sulfonic acid) radical i.e (ABTS ${ }^{\circ}$ ) which has a blue-green colour and a TEAC value given by comparing colour reduction induced by the compound to that induced by a vitamin $\mathrm{E}$ analogue, Trolox [14]. FRAP relies on the ability of antioxidants to reduce complex ferric ion-TPTZ (2,4,6-tri(2-pyridyl)- 1,3,5triazine) which creates a very intense navy blue colored solution whose absorbance gives an estimate of the amount of iron reduced and correlates with the amount of antioxidants present [15]. The oxygen radical absorption capacity (ORAC) assay measures the extent of fluorescence loss from fluorescein as the antioxidants scavenge for peroxyl radicals induced by 2,2'-azobis-(2amidino-propane) dihydrochloride (AAPH) [15]. The extent of loss of fluorescence is an indication of the amount of antioxidants present in the substance being assayed.

The use of different solvents for the extraction of bioactive phytochemicals is traditional to science and the extraction yield is largely dependent on polarity of the solvent and extraction conditions [16]. Expectedly, the nature and amount of bioactive substances and antioxidant capacity of any particular plant extract varies with the solvent of extraction. In this present study, Basella alba leaves were extracted using three common solvents, ethylacetate (EtOAC), methanol $(\mathrm{MeOH})$ and water (aqueous) with the aim of comparing the antioxidant and antityrosinase capacities of the three types of extract. Additionally, the study is expected to establish whether or not there is a correlation between the antioxidant power and the tyrosinase inhibiting abilities of the extract types. 


\section{Materials and Methods}

\section{Plant Material}

Basella alba was harvested fresh from humid locations in Osun state, western Nigeria and used for this study. A sample of this was deposited at the Botany Department of the University of Ibadan, Nigeria with the voucher number UIH-22391, following identification and authentication. The leaves were separated from the stem, washed to remove dust and other particles and then airdried at room temperature. The dried leaf was blended into fine powder using a household electric blender (LOGIK ${ }^{\circledR}$ China).

\section{Preparation of Plant Extracts}

EtOAC and $\mathrm{MeOH}$ extracts were prepared by placing $100 \mathrm{~g}$ of the dry powder of Basella alba leaves in a 2L conical flask and then mixed with $1 \mathrm{~L}$ of organic solvents, ethanol and methanol respectively. These were extracted at room temperature with constant shaking for 48 hours according to the method described by Iloki-Assanga, et al. with slight modifications [17]. The resultant supernatants were filtered and evaporated to dryness using a rotary evaporator (Heidolph 2, Germany) with water bath temperature set at $40^{\circ} \mathrm{C}$. The aqueous extract was prepared by extracting $100 \mathrm{~g}$ of the leaf powder in $1 \mathrm{~L}$ of distilled water as described by Iloki-Assanga, et al. [17]. Dry extracts were stored at $-4^{\circ} \mathrm{C}$ and dissolved in dimethyl sulfoxide (DMSO) to a concentration of $1 \mu \mathrm{g} / \mathrm{ml}$ prior to use.

\section{Determination of Flavonoids}

Two subclasses of flavonoids; flavanols and flavonols were analysed in the extracts. Flavanol content was determined using the method described by McMurrough and McDowell [18]. The assay was based on the reaction between 4-dimethylaminocinnamaldehyde (DMACA) and flavanols to form a characteristic light blue colour that was measured spectrophotometrically at $640 \mathrm{~nm}$. Catechin hydrate in methanol served as stock standard. Flavonol was determined according to the method described by Delcour and Janssens, using Quercetin as the standard for measuring flavonols at $360 \mathrm{~nm}$. All reagents used in both assays were prepared fresh on the day of the assay [19].

\section{Analysis of Antioxidant Capacities}

Three different methods were used to analyze the Antioxidant capacities of the extracts; TEAC was determined according to the method described earlier by Re, et al. [20]. The ABTS radical cation scavenging ability of each extract was determined spectrophotometrically at an absorbance of $734 \mathrm{~nm}$ at $25^{\circ} \mathrm{C}$ after 30minutes of incubation with ABTS mixture at room temperature. TEAC values were given as micromoles Trolox equivalents per gram ( $\mu \mathrm{M} \mathrm{TE} / \mathrm{g})$.

Determination of FRAP was done by a redox-linked colorimetric method as described by Benzie and Strain [21]. Briefly, extract samples were added to FRAP reagent in a 96-well plate and incubated at $37^{\circ} \mathrm{C}$ for 30 minutes. Absorbance was recorded at $593 \mathrm{~nm}$ and the change in absorbance measured after 30 minutes of incubation was directly related to the electron donating antioxidant in the reaction mixture. L-Ascorbic acid was used as a standard and the results were expressed as micromole ascorbic acid equivalents per gram $(\mu \mathrm{M} \mathrm{AAE} / \mathrm{g})$ of extract.

ORAC was determined according to the method of $\mathrm{CaO}$ and Prior which measures antioxidant's scavenging activities against the peroxyl radical of 2,2'-azobis (2aminopropane) dihydrochloride (AAPH) at $37^{\circ} \mathrm{C}[22]$. The test samples were added to fluorescein and loss of florescence corresponded to the extent of decomposition of the radical which is a measure of the antioxidant power of the sample. ORAC values were expressed as micromoles Trolox equivalents $(\mu \mathrm{M}$ TE) per gram of extract.

\section{Determination of Tyrosinase Inhibiting Activity}

The tyrosinase enzyme assay was performed according to the methods described by Chompo, et al. and Vardhan, et al. $[23,24]$. Extract samples were constituted to a stock concentration of $1 \mathrm{mg} / \mathrm{ml}$ by dissolution with DMSO, and further dilutions were then done. Kojic acid as control drug, tyrosinase (500 Units/mL in sodium phosphate buffer) and substrate (2mM L-Tyrosine) were used for the assay as modified in earlier study by Popoola et al., 2015. Enzyme activity was determined by reading the absorbance at $490 \mathrm{~nm}$ and percentage tyrosinase inhibition calculated using the formula:

$$
\times 100
$$$$
\text { Tyrosinase inhibition }(\%)=[(A-B)-(C-D)] /(A-B)
$$

Where, $\mathrm{A}=$ absorbance of the control with the enzyme, $\mathrm{B}$ $=$ absorbance of the control without the enzyme, $\mathrm{C}=$ absorbance of the test sample with the enzyme and $\mathrm{D}=$ absorbance of the test sample without the enzyme. 


\section{Data Analysis}

All data from the assays of antioxidant parameters were analysed and the final results calculated using Microsoft Excel (Version 2010). Results were expressed as mean \pm standard deviation of triplicate values per sample. Graphpad Prism version 5.0 was used for the analysis of tyrosinase activities and calculation of $\mathrm{IC}_{50}$. ANOVA was used for comparism of mean values and $\mathrm{p}<$ 0.05 considered to be statistically significant.

\section{Results}

\section{Flavonoids Concentration and Antioxidant Capacities of Extracts}

The flavonoids content and antioxidant capacities of each of the extract types are presented in Table 1 . The ethylacetate extract of Basella alba leaves contains much higher concentrations of flavanol $(13.44 \pm 0.03 \mu \mathrm{mol} / \mathrm{g})$ and flavonol $(175.54 \pm 0.01 \mu \mathrm{mol} / \mathrm{g})$ when compared to both methanolic and aqueous extracts which contain negligible amounts of the two flavonoids. Incidentally, FRAP value was also highest in the ethylacetate fraction (117.99 $\pm 0.01 \mu \mathrm{mol} \mathrm{AAE} / \mathrm{g}$ ) as compared to methanolic $(46.64 \pm 0.00 \mu \mathrm{mol} \mathrm{AAE} / \mathrm{g})$ and aqueous (48.17 \pm 0.00 $\mu \mathrm{mol}$ AAE/g) leaf extracts of the plant. However, the highest values for TEAC $(439.90 \pm 0.07 \mu \mathrm{mol} \mathrm{TE} / \mathrm{g})$ and ORAC $(1384.40 \pm 90.65 \mu \mathrm{mol} \mathrm{TE} / \mathrm{g})$ were recorded in the aqueous extract when compared to values for methanolic (TEAC; $44.20 \pm 0.03 \mu \mathrm{mol} \mathrm{TE} / \mathrm{g}, \mathrm{ORAC} ; 1286.25 \pm 9.00$ $\mu \mathrm{mol} \mathrm{TE} / \mathrm{g}$ ) and ethylacetate (TEAC; $61.30 \pm 0.07 \mu \mathrm{mol}$ TE/g, ORAC; $483.09 \pm 35.00 \mu \mathrm{mol} \mathrm{TE} / \mathrm{g}$ ) extracts.

\begin{tabular}{|c|c|c|c|c|c|}
\hline Extraction solvent & Flavanol $(\boldsymbol{\mu m o l} / \mathbf{g})$ & Flavonol $(\boldsymbol{\mu m o l} / \mathbf{g})$ & TEAC $(\boldsymbol{\mu m o l ~ T E} / \mathbf{g})$ & FRAP $(\boldsymbol{\mu m o l ~ A A E} / \mathbf{g})$ & ORAC $(\boldsymbol{\mu m o l}$ TE$/ \mathbf{g})$ \\
\hline $\mathrm{EtOAC}$ & $13.44 \pm 0.03$ & $175.54 \pm 0.01$ & $61.30 \pm 0.07$ & $117.99 \pm 0.01$ & $483.09 \pm 35.00$ \\
\hline $\mathrm{MeOH}$ & $0.28 \pm 0.00$ & $89.70 \pm 0.02$ & $44.20 \pm 0.03$ & $46.64 \pm 0.00$ & $1286.25 \pm 9.00$ \\
\hline Aq. & $0.19 \pm 0.00$ & $79.67 \pm 0.01$ & $439.90 \pm 0.07$ & $48.17 \pm 0.00$ & $1384.40 \pm 90.65$ \\
\hline
\end{tabular}

Table 1: Flavonoids content and antioxidant capacities of three different extracts of Basella alba leaves.

$\mu \mathrm{mol} / \mathrm{g}=$ Micromole per gram; $\mu \mathrm{mol}$ TE$/ \mathrm{g}=$ Micromole trolox equivalent per gram; $\mu \mathrm{mol} \mathrm{AAE} / \mathrm{g}=$ Micromole amino acid equivalent per gram; EtOAC = Ethylacetate; $\mathrm{MeOH}=$ Methanol; Aq. =Aqueous

\section{Tyrosinase Inhibiting Activity of Extracts}

The effects of Basella alba extracts on mushroom tyrosinase activity using L-Tyrosine as substrate in an invitro system is reported in Table 2 . The results indicated that all extracts have a direct inhibitory activity against mushroom tyrosinase at effective concentrations of $193.58 \pm 0.02 ; 203.33 \pm 0.02 \& 222.83 \pm 0.03 \mu \mathrm{g} / \mathrm{mL}$ for aqueous, methanol and ethylacetate extracts respectively. These antityrosinase activities of the three extracts were significantly $(p<0.01)$ weaker when compared to that of standard substance, kojic acid at $\mathrm{IC}_{50}$ of $7.33 \pm 1.78$ $\mu \mathrm{g} / \mathrm{mL}$.

\begin{tabular}{|c|c|}
\hline Fraction & Antityrosinase IC $_{\mathbf{5 0}} \pm \mathbf{S D}$ \\
\hline EtOAC & $222.83 \pm 0.03^{*}$ \\
\hline $\mathrm{MeOH}$ & $203.33 \pm 0.02^{*}$ \\
\hline Aq. & $193.58 \pm 0.02^{*}$ \\
\hline Kojic acid & $7.33 \pm 1.78$ \\
\hline
\end{tabular}

Table 2: Tyrosinase inhibiting activity of extracts. ${ }^{*} P<0.01$ vs. Kojic acid; EtOAC = Ethylacetate; $\mathrm{MeOH}=$ Methanol; Aq. =Aqueous

\section{Discussion}

The findings in this study suggest that the aqueous extract of Basella alba leaves exhibit stronger antioxidant properties when compared to methanolic and ethylacetate fractions, despite containing less flavonol and flavanol than the ethylacetate fraction. A significant correlation is said to exist between the total phenolic content and antioxidant activities of Basella alba, which suggests that there may be some phenolic compounds other than flavonol and flavanol that are extractable in aqueous, but not in ethylacetate or methanolic fractions [25]. This may be responsible for the much higher TEAC and ORAC values for the aqueous fraction and further studies to investigate this should involve isolation of active compounds in each extract type for more specific assays. On the other hand, the FRAP reading was observed to be much lower in aqueous compared the ethylacetate fractions, which further confirms the inconsistency that is known to characterize the measurement of total antioxidant capacities and is partly because each assay measures different components of total antioxidant capacity [26-28]. Furthermore, TEAC 


\section{Advances in Clinical Toxicology}

and ORAC readings are believed to be more representative of the antioxidant capacities of the various extract types since these assays directly measure the ability of the extracts to inhibit oxidation, while FRAP is an indirect assay that measures the ability of the extracts to reduce iron complexes [29].

The results further show that all of the extracts from the different solvents displayed similar anti-tyrosinase activity within the range of $193.58-222.83 \mu \mathrm{g} / \mathrm{mL}$. Therefore, the plant Basella alba can be a potential source of further investigation for new anti-tyrosinase agents. The expected active constituent from the quantitative determination of the chemical composition (Table 1) is primarily made up of flavanols in ethylacetate while flavonols are abundant in all the three types of extract. This indicates that the compounds responsible for the observed biological activities are highly extractable in both moderately polar (ethylacetate) and polar (methanol and water) solvents. Although the outcome of this investigation gave moderate antityrosinase activities, this study suggested that Basella alba could play an important role in the regulation of tyrosinase activity and could possibly act as a natural inhibitor of browning reaction and formation of freckles in the skin.

\section{Conclusion}

The findings from this study led to the conclusion that aqueous extraction of Basella alba leaves produced the best yield with regards to antioxidant as well as tyrosinase inhibiting effects of the plant. This also suggests a direct relationship between antioxidant and tyrosinase inhibiting activities of Basella alba. Additionally, a significant part of the antioxidant activities of Basella alba can be attributed to components other than flavonol and flavanol and the plant can be a healthy source of natural antityrosinase compounds.

\section{Acknowledgement}

The authors acknowledge Mr Fanie Rautenbach of the oxidative stress research centre, Cape Peninsula University of Technology, Cape Town, South Africa and Bowen University (of Baptist convention), Nigeria.

\section{Conflict of Interest}

The authors declare that there is no conflict of interest with regard to publishing any aspect of this study

\section{Funding Information}

This work received no specific funding.

\section{References}

1. Lin SM, Lin BH, Hsieh WM, Ko HJ, Liu CD, et al. (2010) Structural Identification and Bioactivities of RedViolet Pigments Present in Basella alba Fruits. J Agric Food Chem 58(19): 10364-10372.

2. Moundipa FP, Kamtchouing P, Koueta N, Tantchou J, Foyang NPR, et al. (1999) Effects of aqueous extract of Hibiscus macranthus and Basella alba in mature rat testis function. J Ethnopharmacol 65(2): 133-139.

3. Arokoyo DS, Seriki AL, Babatunde LD, Ojo AO, Bamidele O (2015) The in-vitro Effect of Aqueous Leaf Extract of Basella alba L. On Osmotic Fragility of Red Blood Cells in Hbss Subjects. European J Biotechnol and Biosci 3(10): 5-10.

4. Baskaran G, Salvamani S, Ahmad SA, Shaharuddin NA, Pattiram PD, et al. (2015) HGM-CoA reductase inhibitory activity and phytocomponent investigation of Basella alba leaf extract as a treatment for hypercholesterolemia. Drug Des Devel Ther 9: 509517.

5. Popoola OK, Marnewick JL, Rautenbach F, Ameer F, Iwuoha EI, et al. (215) Inhibition of Oxidative Stress and Skin Aging-Related Enzymes by Prenylated Chalcones and Other Flavonoids from Helichrysum teretifolium. Molecules 20(4): 7143-7155.

6. Uchida R, Ishikawa S, Tomoda H (2014) Inhibition of tyrosinase activity and melanin pigmentation by 2hydroxytyrosol. Acta Pharmaceutica Sinica B 4(2): 141-145.

7. Pintus F, Spano D, Corona A, Medda R (2015) Antityrosinase activity of Euphorbia characias extracts. Peer J 3: e1305-1314.

8. Saeio K, Chaiyana W, Okonogi S (2011) Antityrosinase and antioxidant activities of essential oils of edible Thai plants. Drug Discovery Therapy 5(3): 144-149.

9. Ramanuj R, Muralidhar ST, Sampad S, Anushree S, Poonam H (2014) Anti-Tyrosinase activity of Stachytarpheta cayennensis in vitro. International Journal of Innovative Research in Science Engineering and Technology 3(7): 14259-14266. 


\section{Advances in Clinical Toxicology}

10. Anand V, Shabina K, Bhawana P (2014) Screening of plant parts for anti-tyrosinase activity by tyrosinase assay using mushroom tyrosinase. Indian J Sci Res 4(1): 134-139.

11. Dao-Mao Y, Ming-An O (2012) Antioxidant and antityrosinase activity from Olea leaf extract depended on seasonal variations and chromatography treatment. Int J Org Chem 2(4): 391-397.

12. Kumar S, Pandey AK (2010) Chemistry and Biological Activities of Flavonoids: An Overview. Scientific World J 2013: 1-16.

13. Ferreyra FML, Rius SP, Casati P (2012) Flavonoids: biosynthesis, biological functions, and biotechnological applications. Front Plant Sci 3: 222.

14. Obon JM, Castelar MR, Cascales JA, Fernandez-Lopez JA (2005) Assessment of the TEAC method for determining the antioxidant capacity of synthetic red food colorants. Food Res Int 38(8-9): 843-845.

15. Pisoschi AM, Negulescu GP (2011) Methods for Total Antioxidant Activity Determination: A Review. Biochem \& Anal Biochem 1: 1.

16. Delfanian M, Kenari RE, Sahari MA (2015) Influence of extraction technique on antioxidant properties and bioactive compounds of loquat fruit (Eriobotrya japonica Lindl.) skin and pulp extract. Food Sci Nutr 3(3): 179-187.

17. Iloki-Assanga SB, Lewis-Lujan LM, Lara-Espinoza CL, Gil-Salido AA, Fernandez-Angulo D, et al. (2015) Solvent effects on phytochemical constituent profiles and antioxidant activities, using four different extraction formulations for analysis of Bucida buceras $\mathrm{L}$ and Phoradendron californicum. BMC Res Notes 8: 396.

18. McMurrough I, McDowell J (1978) Chromatographic separation and automated analysis of flavanols. Anal Biochem 91(1): 92-100.

19. Delcour JA, Janssens de Varebeke D (1985) A new colorimetric assay for flavonoids in pilsner beers. J Inst Brew 91(1): 37-40.
20. Re R, Pellegrini N, Proteggente A, Pannala A, Yang M, et al. (1999) Antioxidant activity applying an improved ABTS radical cation decolorization assay. Free Radic Biol Med 26(9-10): 1231-1237.

21. Benzie IFF, Strain JJ (1999) Ferric reducing/antioxidant power assay: Direct measure of the total antioxidant activity of biological fluids and modified version for simultaneous measurement of total antioxidant power and ascorbic acid concentration. Methods Enzymol 299: 15-27.

22. Cao G, Prior RL (1999) Measurement of oxygen radical absorbance capacity in biological samples. Methods Enzymol 299: 50-62.

23. Chompo J, Upadhyay A, Fukuta M, Tawata S (2012) Effect of Alpinia zerumbet components on antioxidant and skin disease-related enzymes. BMC Complement Altern Med 12: 106-113.

24. Vardhan AK, Pandey B (2014) Screening of plant parts for anti-tyrosinase activity by tyrosinase assay using mushroom tyrosinase. Indian J Sci Res 4(1): 134-139.

25. Roshan A, Naveen KHN, Shruthi SD (2012) A review of Medicinal Importance of Basella alba L. Int J Pharm Sci Drug Res 4(2): 110-114.

26. Jansen EH, Ruskovska T (2013) Comparative analysis of serum (anti)oxidative status parameters in healthy persons. Int J Mol Sci 14(3): 6106-15.

27. Janaszewska A, Bartosz G (2002) Assay of total antioxidant capacity: comparison of four methods as applied to human blood plasma. Scand J Clin Lab Inv 62(3): 231-236.

28. Winter JL, Barber LG, Freeman L, Griessmayr PC, Milbury PE, et al. (2009) Antioxidant status and biomarkers of oxidative stress in dogs with lymphoma. J Vet Intern Med 23(2): 311-316.

29. Rubio CP, Hernandez-Ruiz J, Martinez-Subiela S, Tvarijonaviciute A, Ceron JJ (2016) Spectrophotometric assays for total antioxidant capacity (TAC) in dog serum: an update. BMC Vet Res 12(1): 166. 